\title{
The Selective Conservative Management of Small Traumatic Pneumothorax Following Stab Injuries of the Chest in Emergency Department Patients
}

\author{
Abdel-Maguid Ramadan1, Adel Rizk², Ayman Nosseir³, Tamer Zakhary4, Sarah Waheeb5 \\ ${ }^{1}$ Cardiothoracic Surgery, Faculty of Medicine, Alexandria University, Alexandria, Egypt \\ ${ }^{2}$ Radiodiagnosis, Faculty of Medicine, Alexandria University, Alexandria, Egypt \\ ${ }^{3}$ Cardiothoracic Surgery, Alexandria University, Alexandria, Egypt \\ ${ }^{4}$ Critical Care, Faculty of Medicine, Alexandria University, Alexandria, Egypt \\ ${ }^{5}$ Emergency Medicine, Faculty of Medicine, Alexandria University, Alexandria, Egypt \\ Email: tamer_zakhary@hotmail.com
}

How to cite this paper: Ramadan, A.-M., Rizk, A., Nosseir, A., Zakhary, T. and Waheeb, S. (2017) The Selective Conservative Management of Small Traumatic Pneumothorax Following Stab Injuries of the Chest in Emergency Department Patients. Open Journal of Thoracic Surgery, 7, 29-37. https://doi.org/10.4236/ojts.2017.72005

Received: June 9, 2017

Accepted: June 27, 2017

Published: June 30, 2017

Copyright $\odot 2017$ by authors and Scientific Research Publishing Inc. This work is licensed under the Creative Commons Attribution International License (CC BY 4.0).

http://creativecommons.org/licenses/by/4.0/

cC) $\underset{\mathrm{EY}}{\text { (i) Open Access }}$

\begin{abstract}
Background: Chest trauma is a catastrophic event that affects large number of population and leads to morbidity, disability and mortality. The definition of an occult pneumothorax is uncontested. It is a pneumothorax that was not suspected on the basis of clinical examination or plain radiography, but was ultimately detected with CT and usually treated conservatively. We evaluated the success of selective conservative management of small pneumothorax following stab chest injuries, in Emergency Department patients. Methods: This prospective study was conducted on 30 adult patients admitted to the emergency department with small traumatic pneumothorax following stab injury. All enrolled patients $(n=30)$ were assessed for the following, demographic data, laboratory investigations, chest $\mathrm{x}$-ray and CT scan. The outcomes measured were discharge safely after successful conservative management, Initial conservative then invasive measurement. Results: There was a statistically significant difference between conservative and non-conservative types of management in the incidence of complications after 1 week follow up ( $p=$ 0.001). Conclusion: The majority of asymptomatic small pneumothorax patients following a stab injury can be managed conservatively. Haphazard chest tube insertion and aging may lead to complications in such patients.
\end{abstract}

\section{Keywords}

Emergency, Trauma, Chest, Pneumothorax, Conservative 


\section{Introduction}

Emergency physicians play a vital role in the stabilization and the diagnostic phase of trauma care. The emergency physician is often the sole physician in attendance during the initial phase of resuscitation; what happens in this period often determines the outcome of care [1].

The trauma patient has been defined as an injured person who requires timely diagnosis and treatment of actual or potential injuries by a multidisciplinary team of health care professionals, supported by the appropriate resources to diminish or eliminate the risk of death or permanent disability [2]. Chest trauma is a catastrophic event that affects large number of population and leads to morbidity, disability and mortality. Chest trauma is described as blunt or penetrating. The trauma is classed blunt when the chest wall remains intact and penetrating when the integrity of the chest wall is breached. Most penetrating chest injuries have a mortality rate below $10 \%$ [3].

Pneumothorax occurs when air leaks into the pleural space. This air pushes on the outside of the lung and makes it collapse. In most cases, only a portion of the lung collapses [4]. Patients commonly have pleuritic chest pain, dyspnea, tachypnea, and tachycardia. Breath sounds may be diminished and the affected hemi thorax hyper was resonant to percussion-mainly with larger pneumothorax. Pneumothorax may be described as simple pneumothorax or tension pneumothorax. It can also be classified as open, closed and occult pneumothorax. Positive pressure ventilation can convert an occult pneumothorax to a tension pneumothorax.

The definition of an occult pneumothorax is uncontested. It is a pneumothorax that was not suspected on the basis of clinical examination or plain radiography, but was ultimately detected with $\mathrm{CT}$ and usually treated conservatively [5]. A small, uncomplicated pneumothorax may quickly heal on its own. When the pneumothorax is larger, it needs insertion of an intercostal tube [6]. British thoracic guidelines define a large pneumothorax greater than $2 \mathrm{~cm}$ width at the level of the helium in chest $\mathrm{x}$ ray.

Chest X-ray remains the standard test for diagnosis of thoracic trauma in the Emergency Department. Serial chest radiographs every $6 \mathrm{hrs}$ on the first day after injury to rule out pneumothorax is ideal, but two or three chest X-ray taken every 4 - 6 hrs are sufficient [7]. A Computerized tomography (CT scan) is more sensitive than a chest radiograph in the evaluation of small pneumothorax and pneumomediastinum, although the clinical significance of these occult pneumothoraces is unclear, particularly in the stable non-intubated patient [8].

The occult pneumothorax is being more frequently diagnosed as methods of evaluating and diagnosing trauma patients become more sensitive. At present, CT scan is the gold standard for detecting occult traumatic pneumothorax not apparent on supine chest X-ray radiograph [9]. In this study, we evaluated the success of selective conservative management of small pneumothorax following stab chest injuries, in Emergency Department patients. 


\section{Methods}

After ethical approval for this clinical trial from the local committee of ethics in the faculty of medicine of Alexandria University and the department of Emergency medicine, Informed consent was taken from the next of kin. This prospective study was conducted on 30 adult patients admitted to the emergency department with small traumatic pneumothorax following stab injury in primary survey or secondary survey between the $1^{\text {st }}$ of September 2016 and $2^{\text {nd }}$ January of 2017. Alexandria Main University Hospital is the only tertiary referral trauma center serving a geographical area covering four governorates (Alexandria, MarsaMatrouh, El-Beheira, KafrElsheikh) with an estimated population of 14 million people.

All patients who considered for enrollment were adults with small traumatic pneumothorax (less than $2 \mathrm{~cm}$ from the chest wall at the level of the hilum in chest $\mathrm{x}$ ray) following stab injuries. We excluded patients with blunt chest trauma, hemodynamically unstable, Patients on positive pressure ventilation, Chronicobstructive pulmonary diseases (COPD) patients and any other chest injuries that require exploratory thoracostomy.

All enrolled patients $(n=30)$ were assessed for the following, Demographic data as age, Gender, Date of admission, hospital ID number and mechanism of injury. Clinical assessment including primary survey as (ABCDE) Airway and cervical, breathing, circulation, disability and exposure. Secondary survey as complete history taking, vital signs and Complete physical examination by Inspection, palpation, percussion and auscultation. Laboratory investigations as complete blood picture (CBC), random blood sugar (RBS), blood grouping (AB grouping) and arterial blood gases (ABG).

All enrolled patients $(n=30)$ were subjected for Chest x-ray (PA and lateral view) and Plain CT chest to detect occult pneumothorax. Then, they were Followed up by further clinical assessment, serial ABG analysis and another chest x-ray every 6 hours for 24 hrs. The outcomes measured were discharge safely after successful conservative management, Initial conservative then invasive measurement (tube thoracostomy) and Morbidity and mortality after one week.

\section{Results}

Thirty patients $(n=30)$ were included in this study. Males (27) were more affected than females (3). Their ages ranged between 18 - 60 years with a mean of 30.23. Table 1 shows demographic data of the studied group and the distribution of stab injuries according to the site of trauma. 22 patients were with left sided injury while only 8 with right.

Regarding laboratory investigations, all included patients showed insignificant normal laboratory findings and ABG analysis. The mean hemoglobin was 12.30 g/dl. All patients were with preserved renal function (Table 2).

Regarding the pneumothorax, 25 (83.3\%) patients were diagnosed with chest $\mathrm{x}$-ray while only $5(16.7 \%)$ patients showed normal findings on $\mathrm{x}$-ray and were diagnosed with CT scan (Table 3 ). 
Table 1. Distribution of the studied cases according to demographic data and site of trauma $(n=30)$.

\begin{tabular}{|c|c|c|}
\hline & No. & $\%$ \\
\hline \multicolumn{3}{|l|}{ Sex } \\
\hline Male & 27 & 90 \\
\hline Female & 3 & 10 \\
\hline \multicolumn{3}{|l|}{ Age (years) } \\
\hline $18-30$ & 20 & 66.7 \\
\hline $30-60$ & 10 & 33.3 \\
\hline Min. - Max. & \multicolumn{2}{|c|}{$15.0-57.0$} \\
\hline Mean \pm SD & \multicolumn{2}{|c|}{$30.23 \pm 12.57$} \\
\hline Median & \multicolumn{2}{|c|}{27.50} \\
\hline \multicolumn{3}{|l|}{ Site of injury } \\
\hline Right & 8 & 26.6 \\
\hline Left & 22 & 73.3 \\
\hline
\end{tabular}

Table 2. Laboratory investigations in the studied group $(n=30)$.

\begin{tabular}{cccc}
\hline & Min. - Max. & Mean \pm SD. & Median \\
\hline $\mathrm{ABG}$ & & & \\
$\mathrm{PH}$ & $7.34-7.45$ & $7.40 \pm 0.03$ & 7.40 \\
$\mathrm{PCO}_{2}$ & $30.0-43.0$ & $37.87 \pm 3.10$ & 38.0 \\
$\mathrm{PO}_{2}$ & $88.0-100.0$ & $93.53 \pm 3.06$ & 93.50 \\
$\mathrm{HCO}_{3}$ & $20.0-32.0$ & $24.10 \pm 3.23$ & 24.0 \\
$\mathrm{SO}_{2} \%$ & $92.0-100.0$ & $98.90 \pm 2.76$ & 100.0 \\
$\mathrm{Hbg} / \mathrm{dL}$ & $10.0-16.0$ & $12.30 \pm 1.95$ & 12.0 \\
$\mathrm{WBCs} \times 10^{3} / \mu \mathrm{L}$ & $4.0-11.0$ & $7.13 \pm 2.08$ & 7.0 \\
$\mathrm{Platelet} \mathrm{count/ \mu \textrm {L }}$ & $152.0-350.0$ & $243.80 \pm 63.51$ & 262.0 \\
Urea mg/dL & $15.0-43.0$ & $32.23 \pm 7.03$ & 32.0 \\
Serum Creatinine g/dl & $0.30-1.40$ & $0.88 \pm 0.25$ & 0.90 \\
$\mathrm{RBS} \mathrm{mg} / \mathrm{dL}$ & $101.0-175.0$ & $142.03 \pm 21.15$ & 146.50 \\
\hline
\end{tabular}

Hb: Hemoglobin, WBCs: White blood cells count, RBS: Random blood sugar level.

Table 3. Descriptive analysis of the imaging studies in the studied group $(n=30)$.

\begin{tabular}{ccc}
\hline Pneumothorax & No. & $\%$ \\
\hline X-ray & 25 & 83.3 \\
CT scan & 5 & 16.7 \\
\hline
\end{tabular}

Regarding the type of management, 26 (86.7\%) patients were subjected to conservative management as low flow $\mathrm{O} 2$ therapy, close monitoring and follow up chest X ray every 6 hours to detect any complications early. 4 (13.3\%) patients were subjected to non-conservative interventional management according to the patient's condition as intercostal tube insertion. After 1 week of pf follow up, $6(20 \%)$ patients showed complications as an increase in the size of pneu- 
mothorax, hemothorax, pulmonary contusion and blunt aortic injury. But, 24 (80\%) patients showed no any complications (Table 4).

Twenty-four patients from who subjected to conservative type of management showed no complications while 2 were complicated after 1 week follow up. All patients subjected to non-conservative management were complicated. There was a statistically significant difference between conservative and non-conservative types of management in the incidence of complications after 1 week follow up $(p=0.001)$ (Figure 1). In terms of age, the mean age for the non-complicated patients was 25.5 years while it was 49.17 years in the complicated patients. There was a statistically significant difference between the complicated and noncomplicated patients in their mean of age $(p=0.001)$ (Table 5).

Table 4. Distribution of types of management and 1 week follow up complications in the studied group $(n=30)$.

\begin{tabular}{ccc}
\hline Management & No. & \\
\hline Conservative & & 86.7 \\
Non conservative/intervention & 26 & 13.3 \\
1 week follow up & 4 & 80 \\
Not complicated & & 24 \\
Complicated & 6 & 20 \\
\hline
\end{tabular}

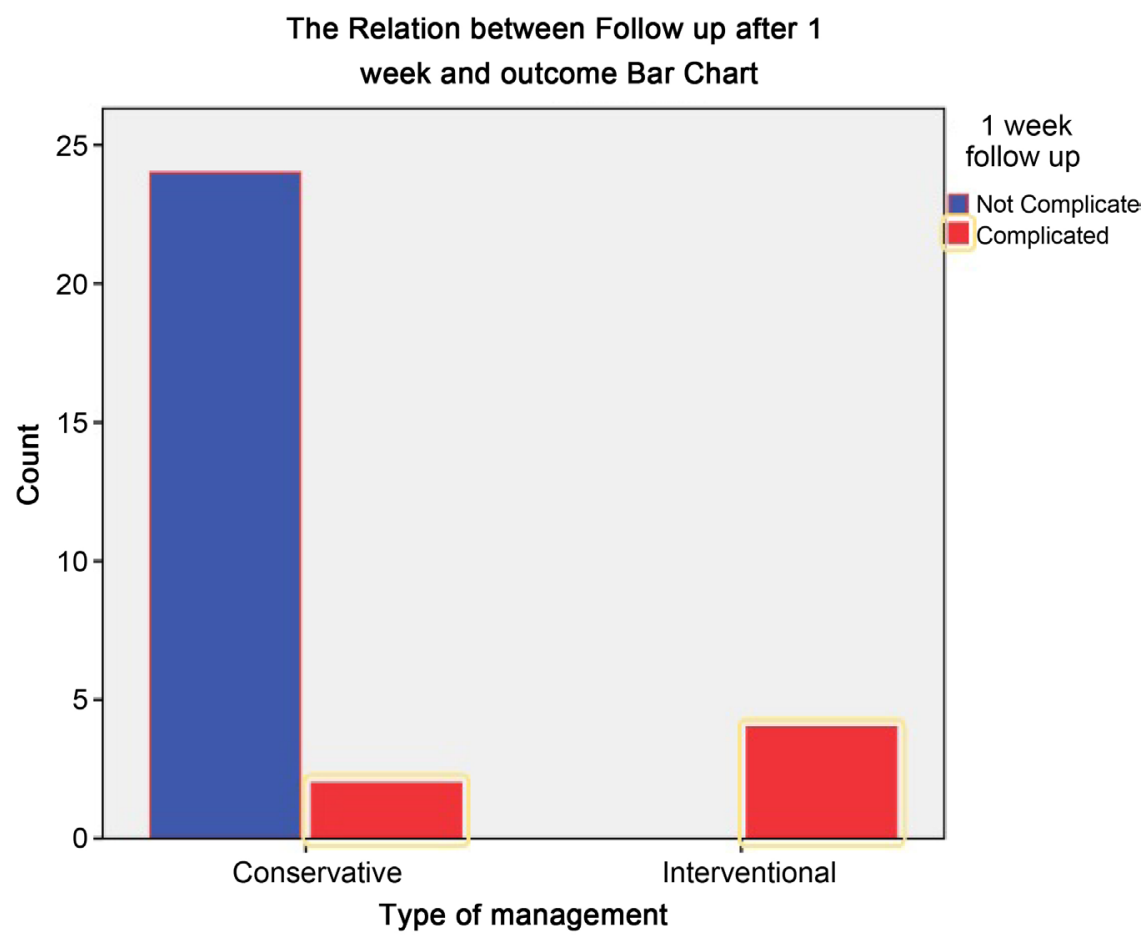

Figure 1. The relation between follow up after 1 week and outcome. Value for PearsonChi square test $18.462 p$-value for Fisher Exact test $0.001^{* *}$ : Statistically significant at $p \leq$ 0.05 . 
Table 5. Relation between Follow up after 1 week and age (years).

\begin{tabular}{lcccc}
\hline & \multicolumn{2}{c}{ Follow up after 1 week } & & t \\
\cline { 2 - 3 } Age (years) & $\begin{array}{c}\text { Not Complicated } \\
(\boldsymbol{n}=\mathbf{2 4})\end{array}$ & $\begin{array}{c}\text { Complicated } \\
(\boldsymbol{n}=6)\end{array}$ & & $\mathrm{p}$ \\
\hline Min. - Max. & $15.0-57.0$ & $45.0-57.0$ & & \\
Mean \pm SD. & $25.50 \pm 8.85$ & $49.17 \pm 4.40$ & $3.461^{*}$ & $0.001^{*}$ \\
Median & 25.0 & 49.0 & & \\
\hline $\mathrm{t}, \mathrm{p}: \mathrm{t}$ and $\mathrm{p}$ values for Student t-test for comparing between the two groups. *: Statistically significant at $p \leq$ \\
0.05.
\end{tabular}

\section{Discussion}

Pneumothorax is very common following penetratingthoracic trauma and is usually treated by the insertion of anintercostal chest tube [7] [10]. There is, however, evidence to suggest that a small, uncomplicated pneumothorax in anasymptomatic patient may be treated conservatively by clinical observation [11]. Traumatic pneumothorax is found in up to $40 \%$ of thoracictrauma patients, and an intercostal chest tube is usually the standard management for these patients [7] [10] [11]. Chest tube insertion is a potentially dangerous procedure which is associated with an overall complication rate of up to $30 \%$ [12] [13].

A follow up study by Muckart in 1985 reviewed 85 patients with pneumothorax and, or haemothorax who were managed conservatively. In the subgroup of 40patients with small-uncomplicated traumatic pneumothorax, only 1 eventually required chest tube, with no associated adverse outcomes [14]. Several articles described the successful application of a selective approach to these injuries, but there was no excusive studies on stab injuries of the chest [15] [16] [17]. Dural et al. in 2005 reviewed 108 patients with pneumothorax and only $43 \%$ from them needed a chest tube [15]. Kong et al. in 2014 reviewed 125 patients with pneumothorax and only $3 \%$ from them needed a chest tube [6]. Our study showed that less than $13.3 \%$ of allpatients enrolled required an ICD. This is consistent with the findings Hegarty [18].

Although much has been written regarding the management of pneumothorax, there is a great deal of confusion surrounding the terminology, which makes it so difficult to extrapolate results from one environment to another. Pneumothorax simply denotes the presence of air within the pleural cavity and may be traumatic or non-traumatic in origin [19]. In the non-trauma setting, most studies tend to focus on spontaneous pneumothorax, which is further divided into primary or secondary [19]. Although there is sufficient evidence to advocate a conservative approach in these patients [19], the underlying pathophysiology is likely to differ from traumatic Pneumothorax [20]. Occult pneumothorax, on the otherhand, specifically describes the entity where chest $\mathrm{x}$-ray is considered normal, but CT scan of the chest reveals evidence of a pneumothorax [21]. Several studies on the management of traumatic pneumothorax often include patients with occult pneumothorax as part of their cohort and, this substantially weakens their generalizability [22] [23]. 


\section{Conclusion}

The majority of asymptomatic small pneumothorax patients following a stab injury can be managed conservatively. We advocate that such patients should be actively observed by medical personnel for signs of clinical deterioration. Haphazard chest tube insertion and aging may lead to complications in such patients. Our recommendation is further studies related to the conservative plan of management especially in the area of Middle East. Limitations of this study were short study time and limited sample size.

\section{Ethics}

After ethical approval for this clinical trial from the local committee of ethics in the faculty of medicine of Alexandria University and the department of Emergency medicine, Informed consents for participating and publishing were taken from the next of kin of patients after approval by emergency department committee.

\section{Acknowledgements}

Not applicable.

\section{Funding}

No funding to declare.

\section{Availability of Data and Materials}

Please contact author for any data requests.

\section{Competing Interests}

The authors declare that they have no competing interests.

\section{References}

[1] Twijnstra, M.J., Moons, K.G., Simmermacher, R.K. and Leenen, L.P. (2010) Regional Trauma System Reduces Mortality and Changes Admission Rates: A before and after Study. Annals of Surgery, 251, 339-343. https://doi.org/10.1097/SLA.0b013e3181c0e910

[2] Fabian, T.C., Peitzman, A.B., Rhodes, M., Schwab, C.W. and Yealy, D.M. (2012) The Trauma Manual: Trauma and Acute Care Surgery. Wolters Kluwer, Alphen aan den Rijn.

[3] Hasler, R.M., Nuesch, E., Juni, P., Bouamra, O., Exadaktylos, A.K. and Lecky, F. (2012) Systolic Blood Pressure below $110 \mathrm{mmHg}$ Is Associated with Increased Mortality in Penetrating Major Trauma Patients: Multicentre Cohort Study. Resuscitation, 83, 476-481. https://doi.org/10.1016/j.resuscitation.2011.10.018

[4] Zarogoulidis, P., Kioumis, I., Pitsiou, G., Porpodis, K., Lampaki, S., Papaiwannou, A., et al. (2014) Pneumothorax: From Definition to Diagnosis and Treatment. Journal of Thoracic Disease, 6, S372-S376.

[5] Wall, S.D., Federle, M.P., Jeffrey, R.B. and Brett, C.M. (1983) CT Diagnosis of Unsuspected Pneumothorax after Blunt Abdominal Trauma. AJR American Journal of 
Roentgenology, 141, 919-921. https://doi.org/10.2214/ajr.141.5.919

[6] Kong, V.Y., Oosthuizen, G.V. and Clarke, D.L. (2015) The Selective Conservative Management of Small Traumatic Pneumothoraces Following Stab Injuries Is Safe: Experience from a High-Volume Trauma Service in South Africa. European Journal of Trauma and Emergency Surgery: Official Publication of the European Trauma Society, 41, 75-79. https://doi.org/10.1007/s00068-014-0426-3

[7] Surgeons ACO (2012) ATLS: Advanced Trauma Life Support for Doctors (Student Course Manual). American College of Surgeons, Chicago, IL.

[8] de Moya, M.A., Seaver, C., Spaniolas, K., Inaba, K., Nguyen, M., Veltman, Y., et al. (2007) Occult Pneumothorax in Trauma Patients: Development of an Objective Scoring System. The Journal of Trauma, 63, 13-17. https://doi.org/10.1097/TA.0b013e31806864fc

[9] Lamb, A.D., Qadan, M. and Gray, A.J. (2007) Detection of Occult Pneumothoraces in the Significantly Injured Adult with Blunt Trauma. European Journal of Emergency Medicine: Official Journal of the European Society for Emergency Medicine, 14, 65-67. https://doi.org/10.1097/01.mej.0000228439.87286.ed

[10] Laws, D., Neville, E. and Duffy, J. (2003) BTS Guidelines for the Insertion of a Chest Drain. Thorax, 58, ii53-ii59. https://doi.org/10.1136/thx.58.suppl_2.ii53

[11] Tebb, Z.D., Talley, B., Macht, M. and Richards, D. (2010) An Argument for the Conservative Management of Small Traumatic Pneumathoraces in Populations with High Prevalence of HIV and Tuberculosis: An Evidence-Based Review of the Literature. International Journal of Emergency Medicine, 3, 391-397. https://doi.org/10.1007/s12245-010-0190-Z

[12] Alrahbi, R., Easton, R., Bendinelli, C., Enninghorst, N., Sisak, K. and Balogh, Z.J. (2012) Intercostal Catheter Insertion: Are We Really Doing Well? ANZ Journal of Surgery, 82, 392-394. https://doi.org/10.1111/j.1445-2197.2012.06093.x

[13] Bailey, R.C. (2000) Complications of Tube Thoracostomy in Trauma. Journal of Accident \& Emergency Medicine, 17, 111-114. https://doi.org/10.1136/emj.17.2.111

[14] Muckart, D.J. (1985) Delayed Pneumothorax and Haemothorax Following Observation for Stab Wounds of the Chest. Injury, 16, 247-248.

[15] Dural, K., Han, S., Yildirim, E., Kocer, B., Kandemir, M., Ozisik, K., et al. (2005) Treatment in Patients with Low Traumatic Pneumothorax Ratio. Tuberkuloz ve toraks, 53, 57-61.

[16] Johnson, G. (1996) Traumatic Pneumothorax: Is a Chest Drain Always Necessary? Journal of Accident \& Emergency Medicine, 13, 173-174. https://doi.org/10.1136/emj.13.3.173

[17] Knottenbelt, J.D. and van der Spuy, J.W. (1990) Traumatic Pneumothorax: A Scheme for Rapid Patient Turnover. Injury, 21, 77-80.

[18] Hegarty, M.M. (1976) A Conservative Approach to Penetrating Injuries of the Chest. Experience with 131 Successive Cases. Injury, 8, 53-59.

[19] MacDuff, A., Arnold, A. and Harvey, J. (2010) Management of Spontaneous Pneumothorax: British Thoracic Society Pleural Disease Guideline 2010. Thorax, 65, 1831. https://doi.org/10.1136/thx.2010.136986

[20] Lesur, O., Delorme, N., Fromaget, J.M., Bernadac, P. and Polu, J.M. (1990) Computed Tomography in the Etiologic Assessment of Idiopathic Spontaneous Pneumothorax. Chest, 98, 341-347. https://doi.org/10.1378/chest.98.2.341

[21] Ernst, A.A., McIntyre, W.A., Weiss, S.J. and Berryman, C. (2012) Occult Pneumothoraces in Acute Trauma Patients. The Western Journal of Emergency Medicine, 13, 437-443. https://doi.org/10.5811/westjem.2011.9.6781 
[22] Bridges, K.G., Welch, G., Silver, M., Schinco, M.A. and Esposito, B. (1993) CT Detection of Occult Pneumothorax in Multiple Trauma Patients. The Journal of Emergency Medicine, 11, 179-186.

[23] Barrios, C., Tran, T., Malinoski, D., Lekawa, M., Dolich, M., Lush, S., et al. (2008) Successful Management of Occult Pneumothorax without Tube Thoracostomy Despite Positive Pressure Ventilation. The American Surgeon, 74, 958-961.

Submit or recommend next manuscript to SCIRP and we will provide best service for you:

Accepting pre-submission inquiries through Email, Facebook, LinkedIn, Twitter, etc. A wide selection of journals (inclusive of 9 subjects, more than 200 journals)

Providing 24-hour high-quality service

User-friendly online submission system

Fair and swift peer-review system

Efficient typesetting and proofreading procedure

Display of the result of downloads and visits, as well as the number of cited articles

Maximum dissemination of your research work

Submit your manuscript at: http://papersubmission.scirp.org/

Or contact ojts@scirp.org 